\title{
Elaboración de un bioactivador a partir de un consorcio microbiano de los géneros: pseudomonas spp., paecilomyces spp. y trichoderma spp. como posible reactivador de suelos erosionados.
}

Development of a bioactivador from a microbial consortium of genres: pseudomonas spp., paecilomyces spp. and trichoderma spp. as a possible reactivador of eroded soils.

Cristina Calderón. ${ }^{1}$ \& Soledad Núñez. ${ }^{2}$

Recibido: 05-07-2017 / Revisado: 17-09-2018 Aceptado: 20-10-2018/ Publicado: 28-11-2018

\begin{abstract}
.
DOI: https://doi.org/10.33262/cienciadigital.v2i4.2..203

A descriptive, correlational and experimental investigation was carried out in the Cacha Parish, Province of Chimborazo; with the aim of developing a bioactivator formed by a microbial consortium with the genera Pseudomonas spp, Paecilomyces spp, Trichoderma spp, to reactivate eroded soils. To do this, the physical, chemical and microbiological characteristics of the eroded soil of the area under study were determined. The interaction between strains of Pseudomonas spp, Paecilomyces spp and Trichoderma spp was finally isolated and evaluated for the elaboration of a bioformula. The study population consisted of the nine communities most affected by the erosion problems that are mainly dedicated to agricultural production, selecting a sample of $1 \mathrm{~kg}$ of soil from each of the most affected communities. It was concluded that the soil of the Cacha Parish, Province of Chimborazo does not have the optimum physicochemical conditions for the proliferation of microorganisms in the soil, so it can be considered essentially arid. In this sense, the application of the bioactivator elaborated from a microbial consortium of $37.5 \%$ of Trichoderma spp., 37.5\% of Paecilomyces spp. and 25\% of Pseudomonas spp. had raised the indicators of fectility in the area under study.
\end{abstract}

\footnotetext{
${ }^{1}$ Escuela Superior Politécnica de Chimborazo, Chimborazo, Ecuador, cristy.gct@gmail.com 2 Escuela Superior Politécnica de Chimborazo, Chimborazo, Ecuador, solenu0408@gmail.com
} 
Keywords: Bioactivator, Erosion, Microorganisms, Fertility, Soil.

\section{Resumen.}

Se realizó una investigación descriptiva, correlacional y experimental en la Parroquia Cacha, Provincia de Chimborazo; con el objetivo de elaborar un bioactivador formado por un consorcio microbiano con los géneros Pseudomonas spp, Paecilomyces spp, Trichoderma spp, para reactivar suelos erosionados. Para ello se determinaron las características físicas, químicas y microbiológicas del suelo erosionado de la zona objeto de estudio. Se aislaron y evaluaron la interacción entre las cepas de Pseudomonas spp, Paecilomyces spp y Trichoderma spp para finalmente la elaboración de un bioformulado. La población de estudio estuvo constituida por las nueve comunidades más afectadas por los problemas de erosión que son dedicadas principalmente a la producción agrícola, seleccionando una muestra de $1 \mathrm{Kg}$ de suelo de cada una de las comunidades más afectadas. Se concluyó que el suelo de la Parroquia Cacha, Provincia de Chimborazo no cuenta con las condiciones fisicoquímicas óptimas para la proliferación de microorganismos en el suelo, por lo que se puede considerar fundamentalmente árido. En este sentido, la aplicación del bioactivador elaborado a partir de un consorcio microbiano de 37,5\% de Trichoderma spp., 37,5\% de Paecilomyces spp. y $25 \%$ de Pseudomonas spp. tuvo elevó los indicadores de fertilidad en el área objeto de estudio.

Palabras Claves: Bioactivador, Erosión, Microorganismos, Fertilidad, Suelo.

\section{Introducción.}

La Parroquia Cacha perteneciente a la provincia de Chimborazo, está conformada por 23 comunidades que se dedican principalmente a la producción agrícola. Es una de las nacionalidades indígenas del Ecuador, pueblo milenario de la nacionalidad Puruhá, tierra y cuna de los reyes Duchicelas que gobernaron la nación Puruhá desde antes de la llegada de los Caras-Shyris. (GAD Cacha, s.f.)

Esta región tiene una zona rural con gran cantidad de áreas enfocadas para el cultivo. Según el INEC (2000), existen 740000 ha de superficie dedicadas a la producción agropecuaria, donde la mayor parte está ocupada por cultivos; encabezando la lista está la papa con una cobertura del $58 \%$ de la superficie de cultivo a nivel zonal, seguida por el tomate de árbol (39\%), el maíz suave en choclo (35\%), maíz suave seco (25\%), caña de azúcar (19\%), arveja (18\%), fréjol seco (12\%), plátano (11\%), café $(6 \%)$, cacao $(3 \%)$ y maíz duro seco (1\%). A estos productos se agregan aquellos que corresponden al sector agroexportador, como son las flores, el brócoli y la alcachofa. 
Hace décadas, el suelo era productivo y rico en nutrientes y se podía sembrar cebada, papas, maíz, etc. Sin embargo, en la actualidad solo crecen árboles de eucalipto y pino. Se cree que por esta pérdida de nutrientes en el suelo las actividades agrícolas han disminuido e incluso se observa el abandono de estos terrenos.

Por otra parte, debido a la práctica del monocultivo en ciertas áreas de Chimborazo se cree que con el tiempo podría causar la erosión del suelo. Por tanto, en aras de estimular una agricultura sostenible, es importante elaborar estrategias que permitan, en la medida en que se hace uso de las bondades que ofrece la tierra, mantener los niveles de nutrientes en un estado óptimo.

Existen múltiples estrategias en la actualidad que posibilitan el mantenimiento de los nutrientes en áreas de cultivos. En la agricultura moderna se aplican altos niveles de fertilizantes minerales y otros agroquímicos. Aunque el uso de estos insumos presenta ventajas inmediatas en el rendimiento de los cultivos, se conoce que el uso de estos en cantidades excesivas puede afectar negativamente la calidad y productividad de los suelos agrícolas. Debido a esta situación, el uso de microorganismos benéficos ha cobrado importancia como alternativa a la fertilización química. (Velázquez \& Ramos, 2015).

Las bacterias promotoras del crecimiento de las plantas (PGPB) favorecen el crecimiento de las mismas a través de diferentes mecanismos, el más importante: la fijación biológica de nitrógeno. (Caballero-Mellado, 2006, pp. 154-161)

Los microorganismos fijadores de nitrógeno, solubilizadores de fósforo y potasio se encuentran ampliamente distribuidos en gran diversidad de suelos y cultivos agrícolas, sólo que algunos muestran mayor actividad que otros y sólo algunas especies pueden ser empleados en la formulación de biofertilizantes con aplicación agrícola. (Velázquez \& Ramos, 2015, pp. 495-499)

Una fuente favorable de material microbiano para inoculación son las PGPB para uso agrícola (tales como Azospirillum sp, Pseudomonas sp, y Bacillus sp) y hongos MA (micorrizas arbusculares). Muchas plantas nativas responden positivamente a la inoculación mejorando su crecimiento. Sin embargo, aquellos microorganismos nativos que crezcan y sobrevivan en suelos con alta dureza son mejores candidatos para inocular las plantas nativas. (Caballero-Mellado, 2006, pp. 154-161)

Las especies del género Trichoderma son los antagonistas más utilizados para el control de enfermedades de plantas producidos por hongos, debido a su ubicuidad, a su facilidad para ser aisladas y cultivadas, a su crecimiento rápido en un gran número de sustratos y a que no atacan a plantas superiores.

En el presente estudio se evalúa la posibilidad de elaborar un bioactivador formado por un consorcio microbiano de Pseudomonas spp, Paecilomyces spp y Trichoderma spp con el 
cual mejorará la calidad del suelo erosionado de la Parroquia Cacha, provincia de Chimborazo.

Se realizará una caracterización física, química y microbiológica del suelo, así como una evaluación de las interacciones entre el consorcio microbiano que permita su correcta disposición para el preparado del bioactivador.

\section{Importancia del problema.}

De acuerdo con observaciones en el área estudiada, se evidenció como el suelo mostró aridez visiblemente, además de escasas especies vegetales, en varias comunidades incluso se observó evidencias de movimientos de tierra, lo que provoca inestabilidad en terrenos, aparecimiento de grietas, así como el cuarteamiento de algunas viviendas, posiblemente por el mencionado movimiento de tierras.

Las comunidades que se encuentran a mayor altura tienen mayor cantidad de problemas ya que no cuentan con un sistema de riego, solo están a expensas de las aguas de lluvia.

Los estudios realizados en la última década han mostrado la existencia de la práctica del monocultivo, en el área objeto de estudio, lo cual ha provocado una erosión calamitosa de este suelo. Surge la necesidad de que esta zona sea recuperada para mejorar la producción agrícola que impulsa económicamente al sector, si es que se concluye que el bioactivador recupera los suelos erosionados.

Además, existen varios estudios donde se ha utilizado microorganismos benéficos y ha cobrado importancia como alternativa a la fertilización química, como las cepas de bacterias (Pseudomonas fluorescens) y hongos capaces de solubilizar fósforo (Paecilomyces lilacinus) y movilizar potasio (Trichoderma harzianum) que han aportado significativamente a la recuperación del suelo. Al consumarse la relación plantamicroorganismo se puede reducir la degradación de los suelos y optimizar el retorno de energía a los sistemas de producción (Velázquez \& Ramos, 2015, p. 497). Es decir que los consorcios microbianos aplicados en suelos erosionados pueden aportar en la recuperación de los mismos.

La presente investigación pretende aumentar la producción en la parroquia mediante la aplicación del bioactivador, incluso esta técnica se podría incluir en el plan nacional del buen vivir, para que se refuerce el sector productivo y se mejore la seguridad alimentaria del país.

\section{Metodología.}

Se realiza una investigación descriptiva, correlacional y experimental en el área determinada de suelo erosionado de la Parroquia Cacha: un área de 1091,53 hectáreas. Para ello se agrupa a 9 comunidades que se dedican principalmente a la producción agrícola, y 
han sido las más afectadas por los problemas de erosión. Donde se selecciona $1 \mathrm{Kg}$ de muestra de suelo de cada una de estas regiones Para el tamaño total de la misma se toman en cuenta solamente 9 comunidades de las más afectadas por la erosión y una no afectada para tener un nivel de comparación en la Tabla 1 se puede evidenciar la superficie en Ha de cada comunidad seleccionada y el total de Ha en agrupación.

El tipo de variables se describen en la Tabla 2

La Parroquia Cacha se encuentra en la Provincia de Chimborazo, Cantón Riobamba, está ubicada a $11 \mathrm{~km}$ al este de la ciudad de Riobamba. Latitud: -1,7000, Longitud: -78.6667. Se identificó la localización y los puntos de muestreo en el suelo, según la susceptibilidad a movimientos de masa, informe presentado por el GAD de la Parroquia Cacha, 2015.

Se toman 38 muestras compuestas por las 1091,53 ha del área identificada. Se realiza muestreo compuesto al azar en las nueve comunidades, 4 muestras por las 8 comunidades afectadas y 6 por la comunidad no afectada. Cada muestra conteniendo de 300 a $500 \mathrm{~g}$ y tomadas a una profundidad de 20 a $30 \mathrm{~cm}$, ya que en esta profundidad se encuentra la mayor abundancia y actividad microbiana (UNIVERSIDAD NACIONAL DE CÓRDOBA, 2015). Se debe tomar aproximadamente 15 submuestras por hectárea en forma de zigzag y al final realizar la mezcla y obtener una muestra compuesta de $500 \mathrm{~g}$.

Las muestras fueron conservadas a $4^{\circ} \mathrm{C}$ hasta su procesamiento.

Se realizan los análisis físico-químicos de las muestras tomadas in situ. Los análisis fueron realizados con una sonda la cual mide $\mathrm{pH}$, Temperatura y Humedad. Estos parámetros fueron caracterizados en las 38 muestras.

En cinco días se organizó a los presidentes de cada comunidad para dividir los días de muestreo. Dos comunidades por día y una el quinto día.

Además, se analiza en el Laboratorio de Servicios Ambiental de la Universidad Nacional de Chimborazo los nutrientes de las muestras tomadas: Carbono, Nitrógeno Fósforo y Potasio iniciales. Con estos parámetros se calculó las relaciones Carbono/Nitrógeno, NPK y porcentaje de Materia Orgánica.

Para la dilución de la muestra se pesa $10 \mathrm{~g}$ de la muestra de suelo homogenizada, en un Erlenmeyer de 250 mL estéril se colocó 10 g de suelo, se diluyó con 90 mL de agua estéril, con esto se logró una dilución $10^{-1}$.

Se prepara 5 tubos de ensayo estériles con un volumen mínimo de $15 \mathrm{~mL}$, con $9 \mathrm{~mL}$ de agua estéril, rotulados desde $10^{-2}$ hasta $10^{-6}$. Con puntas estériles y una micropipeta de volumen $1000 \mu \mathrm{L}$, se lleva $1 \mathrm{~mL}$ de la solución $10^{-1}$ al tubo de ensayo $10^{-2}$, se desecha esta punta y con una nueva se tomó $1 \mathrm{~mL}$ del tubo $10^{-2}$ y se lleva al tubo $10^{-3}$, este proceso se repite hasta el tubo $10^{-6}$. 
En cajas petri con agar nutritivo se coloca $0,1 \mathrm{~mL}$ de las diluciones $10^{-2}$ hasta $10^{-6}$ y se realiza siembra en superficie, extendiendo todo el volumen colocado en el agar cuidadosamente con la ayuda de una varilla de vidrio doblada en "L" previamente esterilizada a la flama del mechero y enfriada. (Aquiahuatl R. \& Pérez C., 2004, pp. 68-70).

Para el recuento de heterótrofos se realizan diluciones seriadas con la muestra tomada en cada punto, en caja por superficie por repetición. Se realizan diluciones seriadas hasta la concentración $10^{-5}$. Se siembra la dilución $10^{-2}, 10^{-3}, 10^{-4}$ y $10^{-5}$, y tres repeticiones de cada uno. Se incuban a $35^{\circ} \mathrm{C}$ se hizo la lectura a las 48 horas: Se cuentan las colonias que se observaron en cada placa y se calculó el número de unidades formadoras de colonias presentes en $1 \mathrm{~g}$ de muestra. (Passalacqua, et al., 2014, pp. 13-14).

Para las pruebas de antagonismo se utilizan los hongos Trichoderma spp. y Paecilomyces spp previamente cultivados en medio PDA y cultivados durante siete días a $28^{\circ} \mathrm{C}$. Los aislados bacterianos de Pseudomonas se siembran cada uno en caldo nutritivo durante 24 horas, en condiciones de agitación a $150 \mathrm{rpm}$ y temperatura de $30^{\circ} \mathrm{C}$ como describe Tejera, et al. (2012). La concentración celular se ajustó a $10^{8} \mathrm{cel} . / \mathrm{mL}$, tomando como referencia un tubo de referencia a la escala McFarland (Becton, Dickinson and Company, 2005)

Se siembra con la técnica de cultivo dual como describe en su metodología Macedo C., et al. (2012) en el un extremo un bocado de los hongos previamente cultivados con un diámetro de $0,5 \mathrm{~cm}$ y en el otro extremo se inoculo $10 \mathrm{uL}^{-1}$ de las bacterias ajustadas a la escala de McFarland. Fueron sembradas en medio PDA, incubadas a $28^{\circ} \mathrm{C}$ durante 7 días, haciendo un control del diámetro de crecimiento cada 24 horas.

El porcentaje de inhibición se calcula con la Ecuación 2-2, como indica en su metodología Ortíz M., et al. (2013):

$I=\frac{R 1-R 2}{R 1} * 100$

Ecuación: 2. Cálculo del porcentaje de inhibición.

Donde I = Porcentaje de inhibición en el crecimiento del micelio.

R1 = Crecimiento radial del patógeno sobre el lado opuesto, evaluado en la caja Petri

$\mathrm{R} 2$ = Crecimiento radial del patógeno en enfrentamiento

Se midió el grado de inhibición, utilizando la escala que se ha empleado en estudios de micoparasitismo de Trichoderma contra fitopatógenos como indica la escala de Ezziyyani 
et al.., (2004) (Véase Tabla 7-2). Mediante observaciones macroscópicas de las placas con los cultivos duales:

Se realiza un conteo de esporas que hay en el área de cada caja Petri de Trichoderma y Paecilomyces, para esto se utiliza la metodología descrita por Cañedo (2004, p. 41):

Se prepara una suspensión de conidias en agua destilada y con Tween 80 al 0,1\%. En este caso se rasparon las cajas con un asa y se agrega $10 \mathrm{~mL}$ de la solución Tween, la suspensión se filtró a través de una malla o gasa para eliminar grasa o el agar o restos de micelio (Peña S. \& Páez M., 2014), se llevó esta dilución a un volumen conocido. Con una pipeta Pasteur se llena la Cámara de Neubauer con la suspensión de conidias y se las cubre con el cubreobjeto. Se observa al microscopio utilizando el aumento 40xs se cuennta las conidias presentes en los cuadrados elegidos.

Para el conteo de esporas se utiliza la formula y la forma de conteo de la cámara utilizada en este caso la Cámara de Neubauer. Gilchrist et al (2005), citado en (Peña S. \& Páez M., 2014), se las observó con un microscopio óptico con el objetivo de 40x'”

Para conocer el número de levaduras/mL se aplica la siguiente ecuación:

$$
\frac{X \text { levaduras }}{Y \text { cuadros }} \times \frac{\# \text { cuadros cámara }}{\text { Volúmen cámara }} \times \frac{1000 \mathrm{~mm}^{3}}{1 \mathrm{~cm}^{3}(\mathrm{o} 1 \mathrm{~mL})}=\frac{x \text { millones de levaduras }}{\mathrm{mL}}
$$

Ecuación: 3. Cálculo para conocer el número de levaduras.

La suma de levaduras de los Grupos 1 al 5 nos resulta el valor de X levaduras. La cámara de Neubauer contiene 16 cuadros este número viene a ser el valor de Y cuadros. El \# de cuadros de la cámara de Neubauer es de 400 cuadros útiles y tiene un volumen útil de 0,1 $\mathrm{mm}^{3}$

El inóculo de Trichoderma spp y Paecilomyces spp se prepara en un cultivo en agar PDA con el número de esporas previamente contabilizado. Se adiciona una solución de tween 80 a $0,5 \%(\mathrm{v} / \mathrm{v})$ en la caja para el desprendimiento de los conidios.

La suspensión resultante se utiliza para realizar el recuento de conidios en cámara de Neubauer y por con siguiente en un Erlenmeyer de $1000 \mathrm{~mL}$, se inocula el $10 \%$ (v/v) de esta suspensión con concentración de conidios en $200 \mathrm{~mL}$ de caldo nutritivo. Cultivado durante 3 días a una temperatura de $25^{\circ} \mathrm{C}$. (Chávez-García, et al., 2013, pp. 245-251)

Se prepara los aislados bacterianos de Pseudomonas spp. en caldo nutritivo durante 24 horas, en condiciones de agitación a $150 \mathrm{rpm}$ y temperatura de $30^{\circ} \mathrm{C}$ como describe Tejera, 
et al. (2012). La concentración celular se ajusta a $10^{8}$ cel./mL, tomando como patrón un tubo de referencia a la escala McFarland (Becton, Dickinson and Company, 2005)

Para el sustrato se utiliza arroz, melaza y agua destilada gracias al estudio de ChávezGarcía, et al. (2013), siendo este uno de los mejores tratamientos para la producción de hongos biocontroladores. En los tratamientos que se emplea la melaza mencionan que es un medio rico en nutrientes y por lo tanto, facilita el crecimiento de diferentes microorganismos, lo que en este estudio favorece a la microflora del suelo.

En fundas de propileno se coloca $53 \%(\mathrm{p} / \mathrm{p})$ de arroz, $10 \%(\mathrm{p} / \mathrm{p})$ de melaza y $37 \%(\mathrm{p} / \mathrm{p})$ de agua destilada. Todo esto en $1 \mathrm{Kg}$ de mezcla. Posteriormente se sella parcialmente, se autoclava a $115^{\circ} \mathrm{C}, 1$ bar de presión y durante 15 minutos.

Se inocula $20 \mathrm{~mL}$ de cepa. Las soluciones de Trichoderma, Paecilomyces y Pseudomonas se ajustaron a $75 \%$ de hongos y $25 \%$ de bacterias. Es decir: 37,5\% de Trichoderma spp., $37,5 \%$ de Paecilomyces spp. y $25 \%$ de Pseudomonas spp. Se sellaron las fundas herméticamente y se incubaron en una cámara adaptada con lámparas fluorescentes como se muestra en la Figura 7-2 en períodos alternnos luz-oscuridad a $35^{\circ} \mathrm{C}$, durante 10 días.

Los preparados realizados anteriormente se inocularon directamente en el suelo. Se prepararon macetas para las pruebas como muestra la Figura 8-2, con $1 \mathrm{~kg}$ entre las muestras de suelo y el bioactivador, con concentración de $90 \%$ (p/p) de muestra y $10 \%$ (p/p) de bioactivador. Se homogeniza toda la mezcla y se coloca en un lugar que se adapte a condiciones naturales. Diariamente se controla $\mathrm{pH}$, Humedad y Temperatura. Se realiza un control de descomposición de la materia orgánica a los quince días por observación.

El suelo es una mezcla de diferentes tamaños de partículas de roca y ocasionalmente puede tener materia orgánica, con esto se sabe la cantidad de arena, cieno y arcilla. Con estas cantidades se pudo saber la cantidad de agregados que hay en el suelo lo que influye en los microorganismos. Coyne (2000, p. 138) menciona que "los microorganismos suelen ser más numerosos en los horizontes del suelo ricos en ciento y arcilla, que en capas arenosas intermedias".

Para esto se siguió la metodología de Duque Escobar \& Escobar P., (2016, pp. 48-70): Se seca el suelo al aire y se hizo pasar por una serie de tamices, de aperturas diferentes, decrecientes y conocidos, de arriba hacia abajo. Empieza el tamizado en el tamiz de mayor apertura y termina en una base al final de igual tamaño que los demás tamices y recibe el material más fino. Ademas se tapa todo el juego de tamices para evitar la pérdida de finos. Con un agitador mecánico se sacude el juego de tamices y se pesa por separado el suelo retenido en cada malla, para sacar el porcentaje de los diferentes diámetros y se compara con la clasificación europea del tamaño de particulas. 
Para conocer el índice de germinación se sigue el procedimiento de Gavilanes Terán (2014): se pesa $10 \mathrm{~g}$ de muestra y se le añade $15 \mathrm{~mL}$ de agua destilada, a esta solución se deja 30 minutos en reposo. Pasado el tiempo se le añade $67,5 \mathrm{~mL}$ de agua y se agita. Se filtra al vacío en matraces buckner con un papel filtro de 0,45 micras. Se toma $5 \mathrm{~mL}$ de muestra que se coloca sobre una caja petri con papel filtro y 8 semillas de rábano. Por cada muestra se realiza 10 repeticiones. Se tapan las cajas con papel aluminio para evitar que se sequen y se incuban a $28^{\circ} \mathrm{C}$. Después de 48 horas se sacaron las cajas de la estufa y se añade $1 \mathrm{~mL}$ de alcohol al 50\% para inhibir el crecimiento. Se conta las semillas que germinaron y se mide la longitud de la raíz con el pie de rey (véase Figura 10-2). Este procedimiento se realiza para las muestras sin bioactivador y con bioactivador, es decir 18 muestras y el porcentaje de crecimiento de la raíz \%L y el índice de germinación (IG), que se obtiene con la siguiente formula: $\mathrm{IG}=(\% \mathrm{G} \times \% \mathrm{~L}) / 100$

Se envia las muestras aplicado el bioactivador después de 15 días de tratamiento para el análisis del porcentaje de Carbono y Nitrógeno como factores principales de control de efectividad en el Laboratorio de Servicios Ambientales de a UNACH.

Para el análisis biológico se repite el proceso de recuento de heterótrofos (refiérase al apartado 2.6 de este capítulo) de las muestras 15 días después de aplicadas el bioactivador.

\section{Resultados.}

Se realizaron análisis Físico - Químicos in situ. En la tabla 3 se muestran los resultados de los análisis antes de aplicar el bioactivador.

Es complejo contabilizar la población total de las bacterias en el suelo, puesto que no hay un medio de cultivo único adecuado para todos los grupos, una situación normal en el suelo presenta un crecimiento de $10^{8}$ a $10^{10}$ (Coyne, 2000, p. 108) La Gráfica 1 indica una población microbiana por debajo de la normal, lo que supone una baja actividad microbiana.

De acuerdo a la escala propuesta por (Bell, et al., 1982) el ensayo no muestra antagonismo entre los hongos Trichoderma spp y Paecilomyces spp, lo que supone se puede considerar de clase 3 ya que ninguno parece dominar al otro. Después de 7 días de incubación a $28^{\circ} \mathrm{C}$ y control diario, mediante observación podríamos afirmar que hay una relación benéfica entre los hongos.

La interacción entre Trichoderma spp., y Paecilomyces spp., es benéfica, ninguno causa efectos perjudiciales hacia el otro, y conviven en un medio asociante. Se realiza cinco repeticiones del ensayo, en todos muestra que Trichoderma spp., crecía a una mayor velocidad que Paecilomyces spp., y esto se puede corroborar con el ensayo "control", lo que ayuda a entender el crecimiento rápido de Trichoderma spp., cuando las dos cepas se estabilizaron al sexto día se pudo notar el crecimiento de Paecilomyces spp. Los dos 
hongos crecieron uno sobre el otro, no presentaron un halo de inhibición, lo que hace suponer que ninguno de los dos inhibe el crecimiento del otro y pueden actuar conjuntamente para un beneficio mutuo.

La presencia de Paecilomyces fue verificada mas tarde que las otras especies, esto se presume que se debe al crecimiento lento que presenta Paecilomyces obtenido en los ensayos de control, ya que Trichoderma coloniza toda la caja mientras Paecilomyces no logra ocupar todo el medio a los 7 días de incubación. Por la interacción benéfica entre estos dos géneros se decide elaborar el bioactivador con dichos hongos.

\section{Bacteria - Hongo}

Se realizan 6 interacciones para las pruebas de antagonismo entre bacteria y hongo. Cada una con dos repeticiones. Los resultados fueron: antagonismo entre $P$. aeruginosa vs Trichoderma spp, la bacteria inhibe el crecimiento normal del hongo. Relación benéfica entre $R$. palustris vs Trichoderma spp y Paecilomyces spp y el mismo resultado para Pseudomonas spp vs Trichoderma spp y Paecilomyces spp

La interacción entre $P$. aeruginosa con los hongos Trichoderma y Paecilomyces es negativa, ya que presenta un halo de inhibición, lo que se busca es que la bacteria permita el normal crecimiento al hongo como se puede observar en las interacciones de Pseudomonas spp. y Rhodopseudomonas palustris, en la interacción con este último el resultado con Paecilomyces spp no fue tan favorable como con Trichoderma spp el cual logro ocupar el total del medio, mientras que Paecilomyces spp logra interacción mas no asociación. Estas interacciones se las puede considerar como grado de inhibición clase 4 por invasión total de la superficie de la bacteria y esporulación sobre ella, pero ninguno parece dominar al otro. La interacción de los hongos con $P$. aeruginosa muestra grado de inhibición 0 ya que presenta ninguna invasión de la superficie de la colonia de la bacteria.

De acuerdo a estudios por Olusola A., et al. (2017) P. aeruginosa es antagonista ante patógenos, en este estudio realizan tratamiento con doble inoculación con el hongo Trichoderma harzianum menciona que $P$. aeruginosa funcionó en el tratamiento mejor por sí solo que en combinacion de ambos organismos, este resultado podría suponer es debido a la inhibición que esta bacteria tiene con Trichoderma spp; Paecilomyces spp. es un hongo con características similares en cuanto a funcion y requerimientos energéticos por lo que también presenta inhibición en el crecimiento, con un halo promedio de las tres repeticiones de 0,50 cm con Trichoderma spp. y de 0,72 cm con Paecilomyces spp.

Debido a estos resultados se elige la cepa de Pseudomonas spp. para actuar en conjunto con Trichoderma spp y Paecilomyces spp. en el bioactivador como controlador de patógenos, además que aporta en el crecimiento de las plantas al colonizar los órganos subterráneos de las mismas, como menciona Cazorla (2000). 
Para la inoculación del bioactivador se evalúa el número de esporas por caja dando como

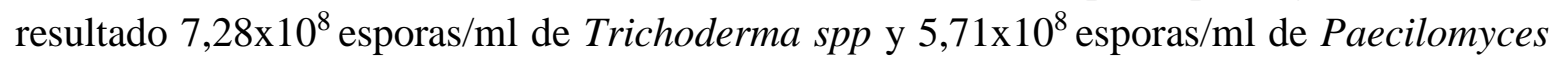
spp promedios de las tres repeticiones que se realiza, se muestra detalladamente en la Tabla 4.

Se obtuvo el bioactivador con las proporciones mencionadas en metodología, el número de esporas obtenidas por caja y siete días de incubación intercaladas entre luz y oscuridad, la Figura 18-3 muestra el crecimiento evidente de la especie Trichoderma spp por las pigmentaciones verdes y por las pigmentaciones rosadas el crecimiento de Paecilomyces spp.

El suelo muestra grandes cantidades de agregados que según (Coyne, 2000) se adhieren entre sí la arena, el cieno y la arcilla para formarlos, esto podría explicar porque la cantidad de arcilla y limo son casi nulas. El suelo presentó una alta cantidad de humedad, otro posible suceso de la baja cantidad de arcilla y limo. Este hecho, puede repercutir en el tiempo de secado con una extensión de 30 minutos. Al hacer las pruebas texturales de campo se pudo obtener que el suelo presentaba características arcillosas o arcillo limoso, ya que se hizo una bola con el suelo en la mano y al rotarla en la misma mantuvo su forma, y entre otras pruebas similares que los caracterizaban como posibles suelos arcillosos y limosos.

Los resultados a simple vista son favorables en el suelo después de aplicado el bioactivador.

Las barras azules en la Gráfica 2 muestra el índice que alcanzaron, donde se puede apreciar que llegan con corta diferencia al $80 \%$ de germinación. Para comprobar estadísticamente que hay diferencias significativas entre los dos tratamientos se asume con normalidad cuando los datos pasan de 50 muestras. Se compara las medias con la Prueba T para muestras independientes en el programa IBM SPSS versión 22.

Por otra parte no existen diferencias significativas en el $\mathrm{pH}$ por efecto de los tratamientos aplicados. Las mediciones iniciales en cuanto al pH estaban dentro de las zonas adecuadas. El gráfico 3 muestra la variación del $\mathrm{pH}$ antes y después del tratamiento.

En relación a la humedad, las mediciones iniciales en cuanto al porcentaje de Humedad eran visiblemente bajos, este parámetro es uno de los cruciales cuando hablamos de suelos erosionados, la capacidad baja de retención de humedad que tienen estos suelos no les permite mantener este parámetro en buen estado, pero después de aplicado el bioactivador se puede notar que la humedad ha subido significativamente, y esto se demuestra estadísticamente ya que si hay diferencias entre las muestras iniciales sin bioactivador y las muestras finales que presentaron altos porcentajes de humedad, algunos por encima de la ideal como se puede observar en la Gráfica 4. 
Existen diferencias significativas en el porcentaje de Carbono por efecto de los tratamientos aplicados. En cuanto a los porcentajes de Carbono iniciales solo la muestra número 5 perteneciente a la comunidad Cauñag se presentaba por debajo de los límites, es decir, se caracterizaba como \%C muy pobre y tuvo una notable mejora de $0,95 \%$ a $4,73 \%$, como se puede observar en la Gráfica 5, mientras que los otros parámetros se encontraban al borde de lo ideal antes de aplicado el bioactivador, y como se puede observar la mejora es notable.

El porcentaje de Nitrógeno difiere significativamente de la muestra inicial por efecto de los tratamientos aplicados. El porcentaje de nitrógeno aumenta en un 40,14\% como muestra la Gráfica 6, comparando las medias, observando independientemente por muestra en la Gráfica se puede observar que en la M1 y M2 se obtuvo el mismo y por debajo del suelo sin bioactivador.

No existen diferencias significativas en la relación Carbono/Nitrógeno por efecto de los tratamientos aplicados. Las medidas antes del tratamiento muestran un buen rendimiento, mientras se encuentren en el rango de BAJA indica que la materia orgánica da un buen suministro de N, K y S al suelo. La muestra M4 y M6 como se observa en la Gráfica 7 se encontraban en una relación C/N ALTA lo que indica que el suministro de nitrógeno, fósforo y azufre es más lento pero gracias al tratamiento con el bioactivador desarrollado, se puede apreciar que todas las muestras se encuentran en una relación baja lo que es favorable con el suelo en cuanto a los nutrientes.

El aporte materia orgánica en el suelo beneficia la interacción de los microorganismos y los nutrientes disponibles para estos y las plantas. Se evidencian una mejoras comparando las medias de los tratamientos sin bioactivador y con bioactivador. Además, se puede apreciar en el Gráfico 8 que la muestra M5 tuvo una mejora notable en cuanto a este parámetro, ya que sin el tratamiento se encuentra en la zona de materia orgánica muy pobre. Con la aplicación del bioactivador todas las muestras se encuentran en la zona de porcentaje de materia orgánica rico.

El aporte de los nutrientes al suelo por la melaza y el arroz pudieron ser factores que aumentaron la población bacteriana, además de la adición directa del consorcio en el bioactivador. Algunos de los requerimientos esenciales de los microorganismos para crecer son fuentes de carbono, ambientes favorables, $\mathrm{pH}$ y temperatura adecuadas, agua, minerales entre otros factores de crecimiento que al aumentar la población se puede deducir que estos parámetros son favorables para la vida microbiana y por ende para la productividad del suelo.

Además, como análisis extra se verifica la presencia de protozoos, un organismo que según (Coyne, 2000) crece cuando hay condiciones ambientales favorables como las que aportan en el crecimiento bacteriano, como el abono, una buena fuente de materia orgánica, 
nutrientes disponibles, condiciones física-químicas apropiadas, temperatura adecuada y un buen suministro de agua, además que este microorganismo aporta en la presencia de materia orgánica ya que es un depredador y ayuda en la sobrepoblación de la masa microbiana, por lo que se obtiene un buen equilibrio. Se encontró presencia de estos organismos así que se puede decir que el suelo aplicado el bioactivador es favorable para la vida microbiana y adecuado para la producción agrícola.

\section{Discusión.}

En la caracterización física-química del suelo se obtuvo un $\mathrm{pH}$ en las muestras entre neutro y básico por lo que se puede considerar suelo árido. La humedad se encontró muy por debajo del límite, todas las muestras tenían escasa humedad oscilando entre $20 \%$ y $35 \%$, lo que es considerado por la FAO una humedad no apropiada para la proliferación de microorganismos en el suelo. Los nutrientes como el Carbono se determinó que la mayor parte de las muestras se encuentra en buenas condiciones, la muestra M5 de la comunidad Cauñag presentó un \% C muy pobre de $0,95 \%$, Las demás muestras sobrepasaban el $2 \%$ de Carbono. El porcentaje de Nitrógeno ayudó a calcular la relación Carbono/Nitrógeno, las muestras de Pucará Quinche M4 y San Antonio de Bashug M6 presentaron una relación $\mathrm{C} / \mathrm{N}$ alta lo que quiere decir que el suministro de nitrógeno, fósforo y azufre es más lento. Mientras que en la muestra de Verdepamba M7 la relación es media que indica existe un suministro normal de nutrientes por la descomposición de la materia orgánica, las demás muestras presentaron una relación baja y esto quiere decir que el aporte de nitrógeno, potasio y azufre al suelo es bueno. En cuanto a la materia orgánica todas las muestras excepto la M5 se encontraban en los valores ricos de cantidad de materia orgánica presente en el suelo, la M5 de Cauñag se encontraba con un porcentaje de materia orgánica muy pobre.

En la realización de pruebas de antagonismo entre las cepas de Paecilomyces spp y Trichoderma spp, no se encontraron antagonismos entre los hongos, lo que supone se puede considerar de clase 3 según la escala propuesta por Bell, et al. (1982) ya que ninguno parece dominar al otro, una interacción benéfica, es decir que ninguno de los dos hongos causa efectos perjudiciales hacia el otro, conviven en un medio asociante. En los ensayos Bacteria-Hongo se realizó seis interacciones resultando antagonismo entre $P$. aeruginosa vs Trichoderma spp, la bacteria inhibe el crecimiento normal del hongo; relación benéfica entre $R$. palustris vs Trichoderma spp y Paecilomyces spp y el mismo resultado para Pseudomonas spp vs Trichoderma spp y Paecilomyces spp. La interacción más favorable fue con la cepa Pseudomonas spp. la cual se eligió para actuar en conjunto con Trichoderma spp y Paecilomyces spp en consorcio en el bioactivador.

Se elaboró el bioactivador con un consorcio microbiano contenido por $37,5 \%$ de Trichoderma spp., 37,5\% de Paecilomyces spp. y 25\% de Pseudomonas spp. en un sustrato 
de $53 \%(\mathrm{p} / \mathrm{p})$ de arroz, $10 \%(\mathrm{p} / \mathrm{p})$ de melaza y $37 \%(\mathrm{p} / \mathrm{p})$ de agua destilada. En un $1 \mathrm{Kg}$ de preparado. Se determinó que el número de esporas utilizado para la inoculación de este

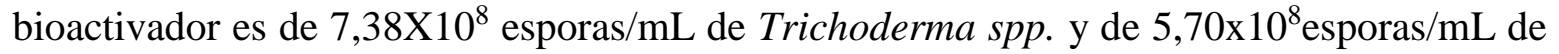
Paecilomyces spp. En cuanto a Pseudomonas spp se inocula $1 \times 10^{8}$ celulas $/ \mathrm{mL}$.

A partir del análisis para el control de efectividad del bioactivador, se realizó el índice de germinación para las muestras sin bioactivador (SB) y con bioactivador (CB) en el que se obtuvo una media de $25,10 \%$ en el tratamiento SB, y $74.90 \%$ en el tratamiento $\mathrm{CB}$. En cuanto a análisis físico-químicos se obtuvo que en pH se logró el equilibrio de las muestras, hallando que no existen diferencias significativas por efecto de los tratamientos aplicados.

Respecto al porcentaje de humedad se determinó que la acción del bioactivador fue beneficiosa en cuanto a humedad ya que se obtuvo una mejora de 53,68\% y las muestras aplicadas el tratamiento se ubicaron en el rango de humedad adecuada. En cuanto al porcentaje de Carbono las diferencias fueron significativas y obtuvo una mejora en cuanto a este parámetro, las muestras con el bioactivador se encuentran en lo normal de un suelo fértil. Respecto al porcentaje de Nitrógeno mostró diferencias significativas entre las muestras con un aumento de 40,14\%. En cuanto a la relación Carbono/Nitrógeno todas las muestras se ajustaron en el rango de relación C/N BAJA que quiere decir que la materia orgánica da un buen suministro de N, K y S al suelo. En cuanto al porcentaje de Materia Orgánica se evidenció una mejora de 24,32\% comparando las medias de los dos tratamientos sin bioactivador y con bioactivador, todas las muestras ajustadas al rango de porcentaje de materia orgánica rico.

En el análisis biológico se determinó una mejora notable ya que antes de la aplicación del bioactivador se encontraban por debajo de la situación normal de UFC/g que debía ser

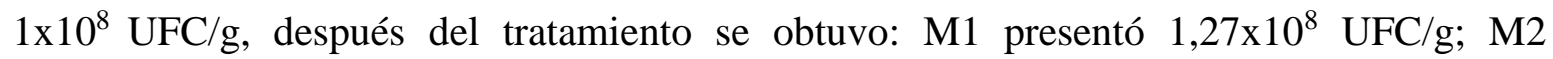

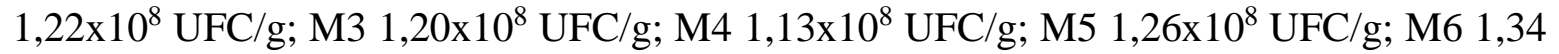

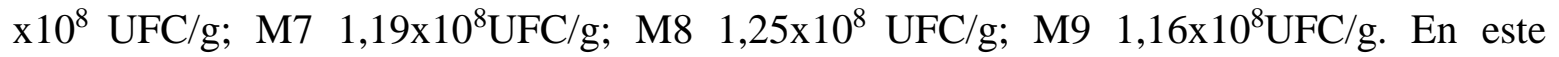
parámetro se obtuvo una diferencia del 70,56\% en comparación de los tratamientos. Además, se halló protozoos en las muestras de suelo con bioactivador, microorganismo que indica existe una buena fuente de materia orgánica, nutrientes disponibles, condiciones física-químicas apropiadas, temperatura adecuada y un buen suministro de agua, además que este microorganismo aporta en la presencia de materia orgánica en el suelo.

\section{Conclusiones.}

- Se pudo determinar que el suelo de la Parroquia Cacha, Provincia de Chimborazo no cuenta con las condiciones fisicoquímicas óptimas para la proliferación de microorganismos en el suelo, por lo que se puede considerar fundamentalmente árido. Esto se pudo constatar en indicadores como el $\mathrm{pH}$ y la humedad que resultaron estar en valores desfavorables para la disponibilidad fértil del suelo. Por 
otra parte, a pesar de que otros indicadores como la materia orgánica, el carbono y el nitrógeno no mostraron valores desfavorables, para que el suelo sea naturalmente fértil es preciso de la interacción de todas las variables en parámetros adecuados. Se confirma de esta manera de acuerdo al análisis fisicoquímico del suelo, la poca fertilidad del mismo.

- Se comprobó que no existe antagonismos entre las cepas de Paecilomyces spp y Trichoderma spp, por lo que establecen una interacción benéfica, es decir que ninguno de los dos hongos causa efectos perjudiciales hacia el otro, conviven en un medio asociante. Lo que no sucedió en la interacción de Bacteria-Hongo que existió cierta tendencia a la inhibición del crecimiento normal del hongo por parte de las bacterias, resultando la relación más favorable con la cepa Pseudomonas spp.

- Se pudo constatar la efectividad del bioactivador, obteniéndose una media de $25,10 \%$ en el tratamiento SB, y $74.90 \%$ en el tratamiento CB. Se logró el equilibrio del $\mathrm{pH}$ de las muestras, hallando que no existen diferencias significativas por efecto de los tratamientos aplicados. Se obtuvo una mejora de 53,68\% de humedad, ubicando a las muestras aplicadas en el rango de humedad adecuada. Las muestras de carbono con el bioactivador se encuentran en lo normal de un suelo fértil. El porcentaje de Nitrógeno mostró diferencias significativas entre las muestras con un aumento de 40,14\%. En cuanto a la relación Carbono/Nitrógeno todas las muestras se ajustaron en el rango de relación $\mathrm{C} / \mathrm{N}$ BAJA que quiere decir que la materia orgánica da un buen suministro de $\mathrm{N}, \mathrm{K}$ y S al suelo. En cuanto al porcentaje de Materia Orgánica se evidenció una mejora de 24,32\% comparando las medias de los dos tratamientos sin bioactivador y con bioactivador, todas las muestras ajustadas al rango de porcentaje de materia orgánica rico. Hubo una mejora general de los indicadores biológicos del suelo que lo predisponen positivamente para la germinación des pues de la aplicación del Bioactivador.

- La elaboración el bioactivador estuvo compuesta por un consorcio microbiano contenido por $37,5 \%$ de Trichoderma spp., 37,5\% de Paecilomyces spp. y $25 \%$ de Pseudomonas spp. en un sustrato de $53 \%$ (p/p) de arroz, $10 \%(\mathrm{p} / \mathrm{p})$ de melaza y $37 \%$ (p/p) de agua destilada, en un $1 \mathrm{Kg}$ de preparado. 


\section{Anexos.}

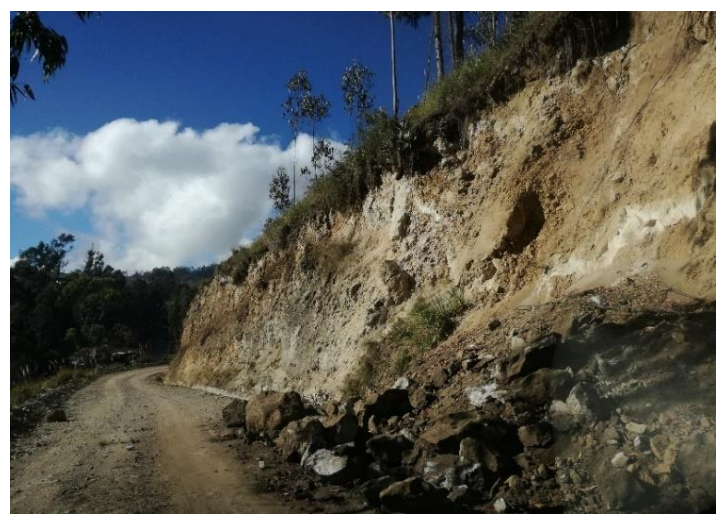

Figura 1 Características de un suelo erosionado. Parroquia Cacha, Provincia de Chimborazo

Fuente: Calderón y Núñez, Ecuador, 2018

Tabla 1 Selección de sectores estratégicos para el estudio

\begin{tabular}{|c|c|c|c|c|}
\hline No. & Superficie(Ha) & Nombre de la comunida & & \\
\hline 3 & 311,63 & Chuyuc (Panadero) & & \\
\hline 6 & 103,02 & Cacha Obraje & \multirow{2}{*}{\multicolumn{2}{|c|}{$\begin{array}{l}\text { Comunidades afectadas por } \\
\text { la erosión }\end{array}$}} \\
\hline 4 & 84,04 & San Pedro & & \\
\hline 2 & 43,76 & Pucara Quinche & \multirow[t]{3}{*}{ घ } & \multirow{2}{*}{$\begin{array}{l}\text { Comunidades no afectadas } \\
\text { representativamente }\end{array}$} \\
\hline 1 & 47,95 & Cauñag & & \\
\hline 7 & 92,41 & San Antonio de Bashug & & \\
\hline 9 & 90,54 & \multicolumn{2}{|l|}{ VERDEPAMBA } & \\
\hline 8 & 128,16 & \multicolumn{2}{|l|}{ Machangara } & \\
\hline 5 & 190,02 & \multicolumn{2}{|l|}{ Cachaton(Pucaratambo) } & \\
\hline Total & 1091,53 & \multicolumn{2}{|l|}{ Ha } & \\
\hline
\end{tabular}

Fuente: (Quishpi, et al., 2015) 
Tabla 2 Identificación de variables.

\begin{tabular}{|l|l|l|}
\hline Tipo & Variables & Indicador \\
\hline \multirow{4}{*}{ Dependientes } & \multirow{3}{*}{ Eficiencia del bioactivador } & Índice de germinación en el suelo \\
\cline { 3 - 3 } & & Textura del suelo \\
\cline { 2 - 3 } & $\mathrm{pH}$ & UFC/g del suelo \\
\hline \multirow{4}{*}{ Independientes } & Humedad & \%otencial de hidrógeno \\
\cline { 2 - 3 } & Relación C/N & C: N \\
\cline { 2 - 3 } & NPK & N: P: K \\
\cline { 2 - 3 } & Crecimiento microbiano & $\begin{array}{l}\text { Unidades Formadoras de Colonias } \\
(\text { UFC) }\end{array}$ \\
\cline { 2 - 3 } & Materia Orgánica & $\%$ MO \\
\hline
\end{tabular}

Fuente: Calderón y Núñez, Ecuador, 2018

Tabla 3 Caracterización Física - Química del Suelo Parroquia Cacha, Provincia de Chimborazo

\begin{tabular}{|l|l|l|l|l|l|l|l|l|l|}
\hline \multicolumn{7}{|l|}{ MUESTRAS } \\
\hline PARÁMETROS & M1 & M2 & M3 & M4 & M5 & M6 & M7 & M8 & M9 \\
\hline pH & 7,60 & 7,73 & 6,88 & 7,00 & 6,50 & 6,38 & 6,63 & 7,13 & 6,88 \\
\hline Temperatura $\left({ }^{\circ} \mathrm{C}\right)$ & 7,65 & 12,08 & 9,98 & 16,58 & 16,25 & 15,50 & 15,25 & 15,25 & 15,75 \\
\hline Humedad (\%) & 30,13 & 20,13 & 22,50 & 35,00 & 21,25 & 21,25 & 26,25 & 35,00 & 17,50 \\
\hline Carbono (\%) & 3,57 & 2,11 & 2,03 & 4,87 & 0,42 & 3,02 & 3,34 & 3,29 & 2,22 \\
\hline Nitrógeno (\%) & 0,56 & 1,03 & 0,42 & 0,14 & 0,28 & 0,24 & 0,28 & 0,42 & 0,70 \\
\hline Fósforo $(\mathrm{mg} / \mathrm{kg})$ & 2,46 & 2,44 & 2,10 & 2,58 & 2,76 & 2,73 & 2,82 & 2,40 & 2,10 \\
\hline Potasio $(\mathrm{mg} / \mathrm{kg})$ & 2,18 & 2,51 & 2,81 & 2,34 & 2,94 & 3,08 & 3,16 & 2,20 & 2,56 \\
\hline C/N * & 6,38 & 2,05 & 4,83 & 34,79 & 1,50 & 12,58 & 11,93 & 7,83 & 3,17 \\
\hline NPK** & 7,65 & 4,14 & 5,90 & 2,69 & 3,28 & 4,92 & 2,76 & 8,37 & 14,29 \\
\hline MO*** $(\%)$ & 6,15 & 3,38 & 3,40 & 8,40 & 0,72 & 5,21 & 5,76 & 5,67 & 3,63 \\
\hline
\end{tabular}

Fuente: Laboratorio de Servicios Ambientales, UNACH, 2017

${ }^{*} \mathrm{C} / \mathrm{N}$ (relación Carbono:Nitrógeno), **NPK (Relación Nitrógeno:Fósforo:Potasio), ***MO (Porcentaje de Materia Orgánica) 
Gráfica 1 Bacterias por gramo de suelo

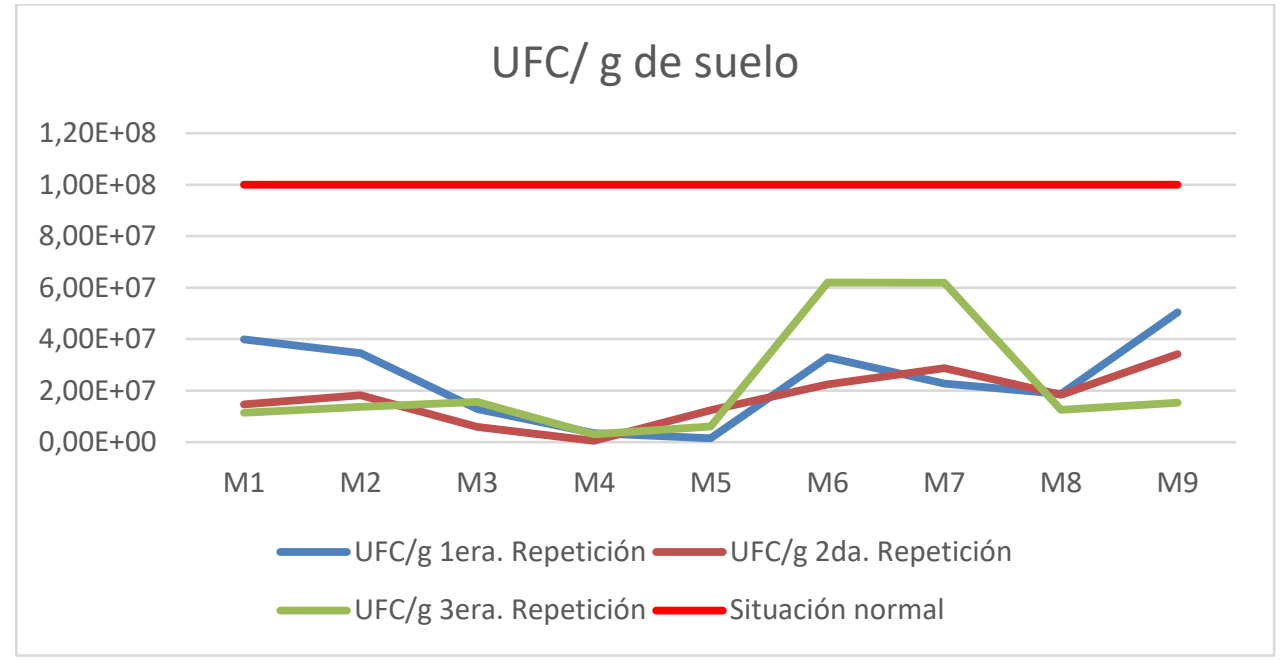

Fuente: Calderón y Núñez, Ecuador, 2018

Tabla 4 Millones de esporas/ml de los hongos Trichoderma spp y Paecilomyces spp

\begin{tabular}{|l|l|l|l|l|l|l|}
\hline Hongos & $\begin{array}{l}\text { Trichoderma } \\
\boldsymbol{1}\end{array}$ & $\begin{array}{l}\text { Trichoderma } \\
\mathbf{2}\end{array}$ & $\begin{array}{l}\text { Trichoderma } \\
\mathbf{3}\end{array}$ & $\begin{array}{l}\text { Paecilomyces } \\
\boldsymbol{1}\end{array}$ & $\begin{array}{l}\text { Paecilomyces } \\
\mathbf{2}\end{array}$ & $\begin{array}{l}\text { Paecilomyces } \\
\mathbf{3}\end{array}$ \\
\hline G1 & 679 & 676 & 650 & 531 & 434 & 520 \\
\hline G2 & 597 & 566 & 550 & 449 & 553 & 500 \\
\hline G3 & 541 & 480 & 569 & 394 & 481 & 380 \\
\hline G4 & 532 & 535 & 520 & 445 & 390 & 399 \\
\hline G5 & 590 & 653 & 598 & 395 & 514 & 450 \\
\hline SUMA & $\mathbf{2 9 3 9}$ & $\mathbf{2 9 1 0}$ & $\mathbf{2 8 8 7}$ & $\mathbf{2 2 1 4}$ & $\mathbf{2 3 7 2}$ & $\mathbf{2 2 4 9}$ \\
\hline \multirow{2}{*}{$\begin{array}{l}\text { X millones de } \\
\text { esporas/mL }\end{array}$} & 734750000 & \begin{tabular}{l}
727500000 \\
\cline { 2 - 6 } \\
\cline { 2 - 6 }
\end{tabular} & 721750000 & 553500000 & 593000000 & 562250000 \\
\hline
\end{tabular}

Fuente: Calderón y Núñez, Ecuador, 2018 
Gráfica 2 Índice de germinación con semillas de rábano

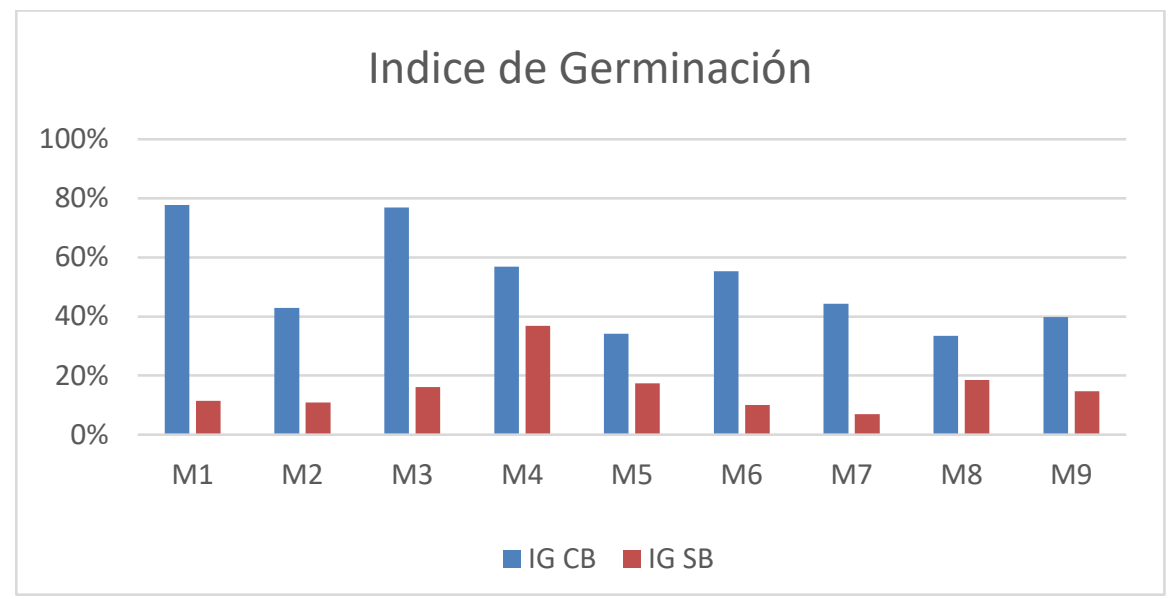

Fuente: Calderón y Núñez, Ecuador, 2018

Figura 2 Mapa geológico de la Parroquia Cacha

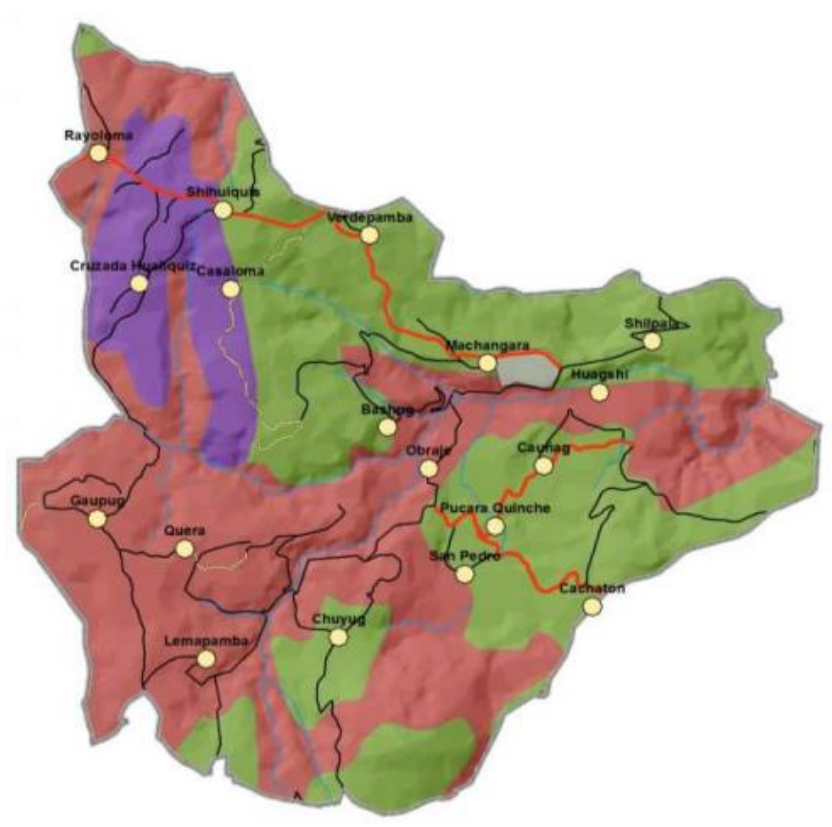

Fuente: (Quishpi, et al., 2015) 
Gráfica $3 \mathrm{pH}$ de los tratamientos Con Bioactivador y Sin Bioactivador

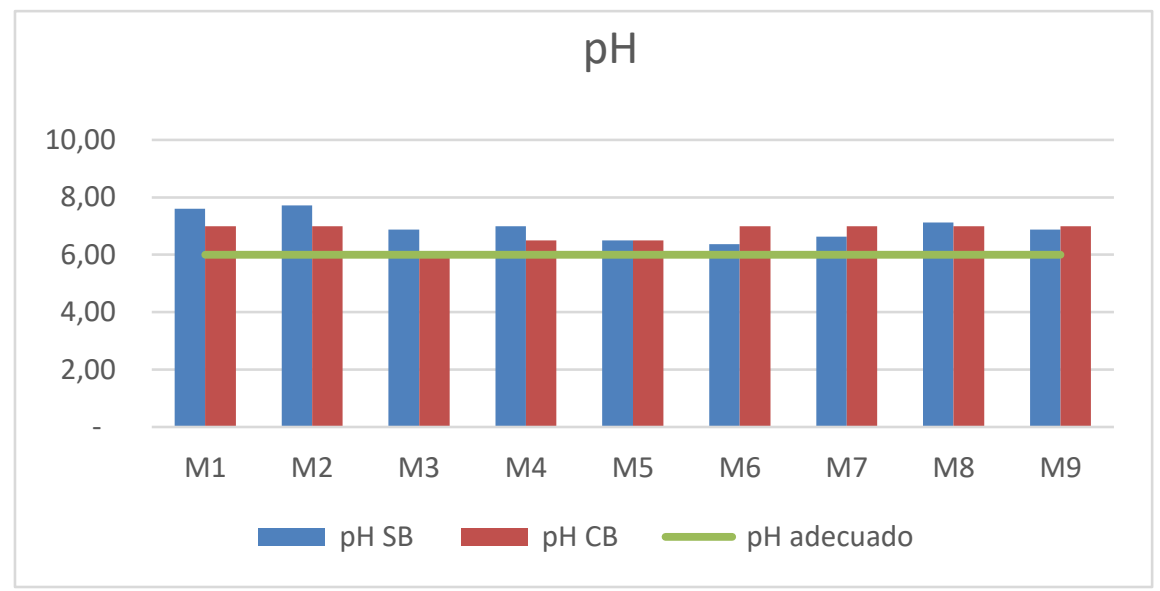

Fuente: Calderón y Núñez, Ecuador, 2018

Gráfica 4 Porcentaje de Humedad de las muestras con bioactivador y sin bioactivador

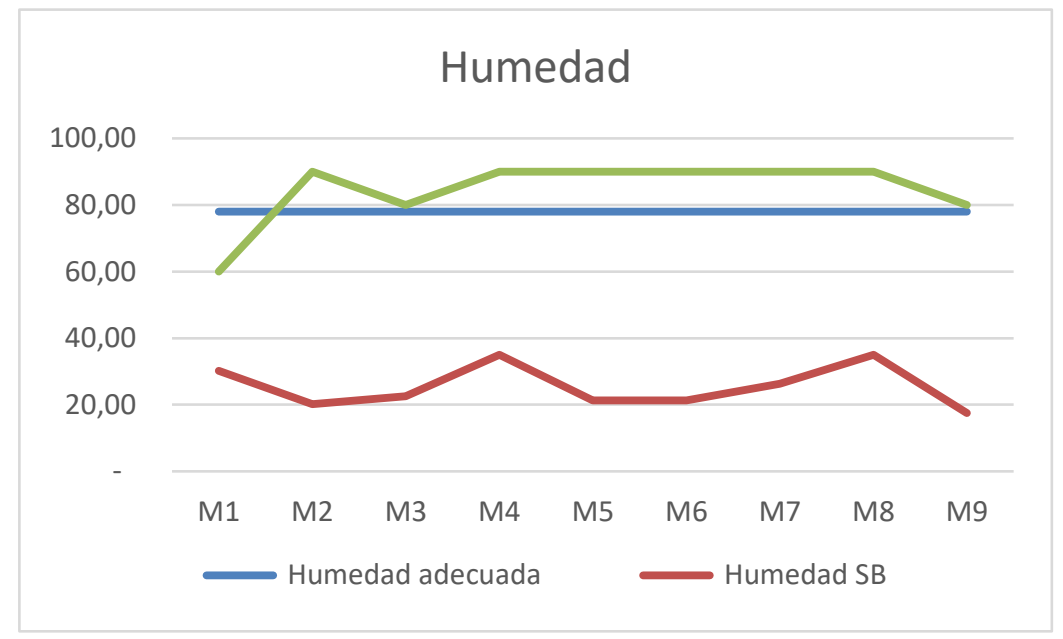

Fuente: Calderón y Núñez, Ecuador, 2018 
Gráfica 5 Porcentaje de Carbono en las muestras sin bioactivador y con bioactivador

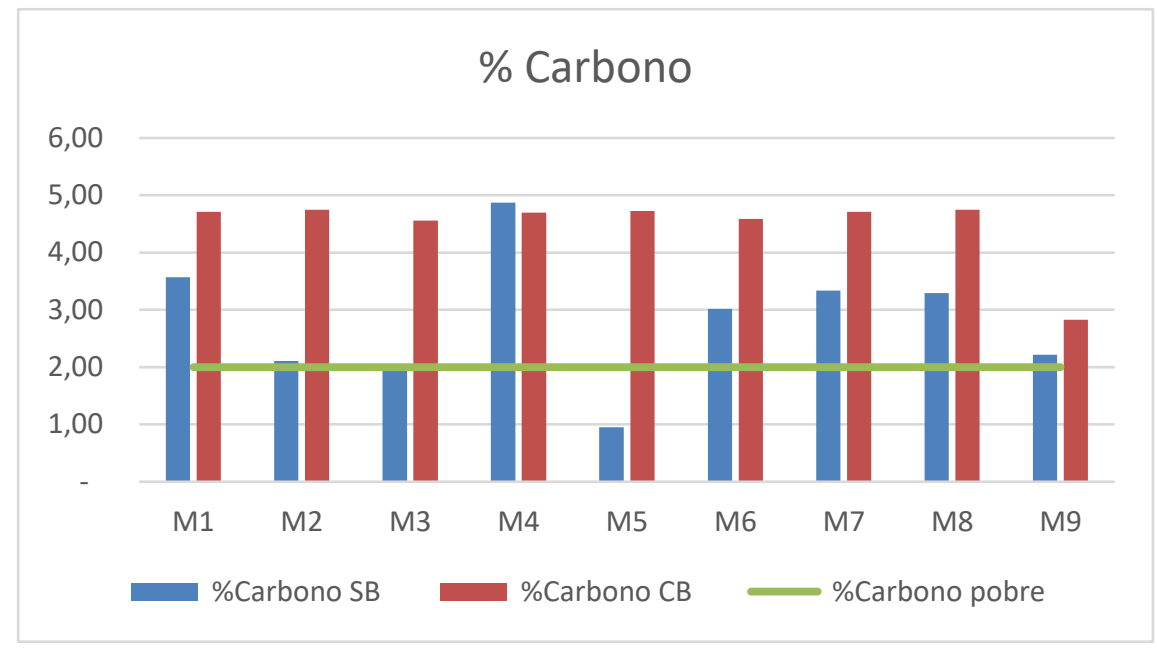

Fuente: Calderón y Núñez, Ecuador, 2018

Gráfica 6 Porcentaje de Nitrógeno con bioactivador y sin bioactivador

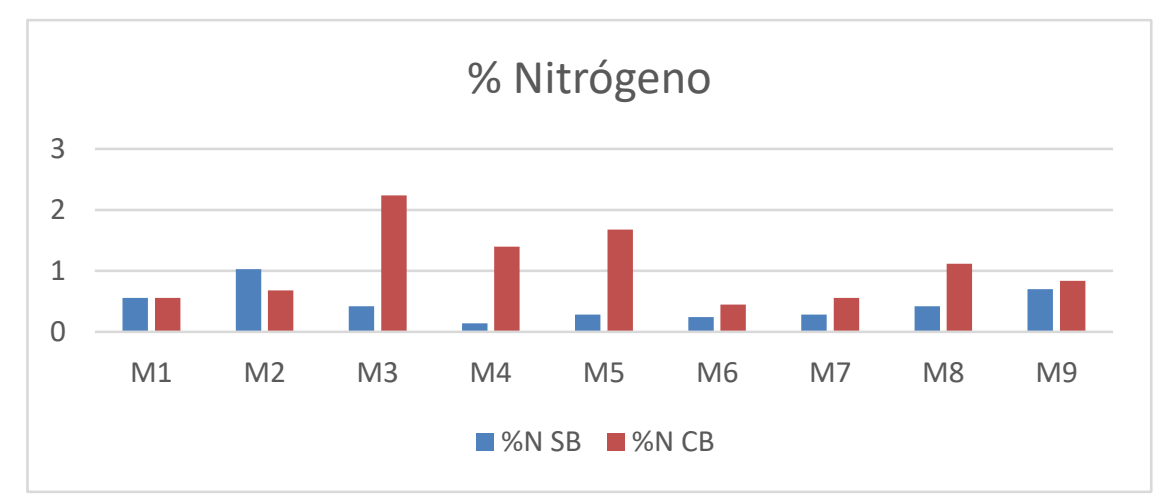

Fuente: Calderón y Núñez, Ecuador, 2018 
Gráfica 7 Relación Carbono/Nitrógeno tratamientos sin bioactivador y con bioactivador

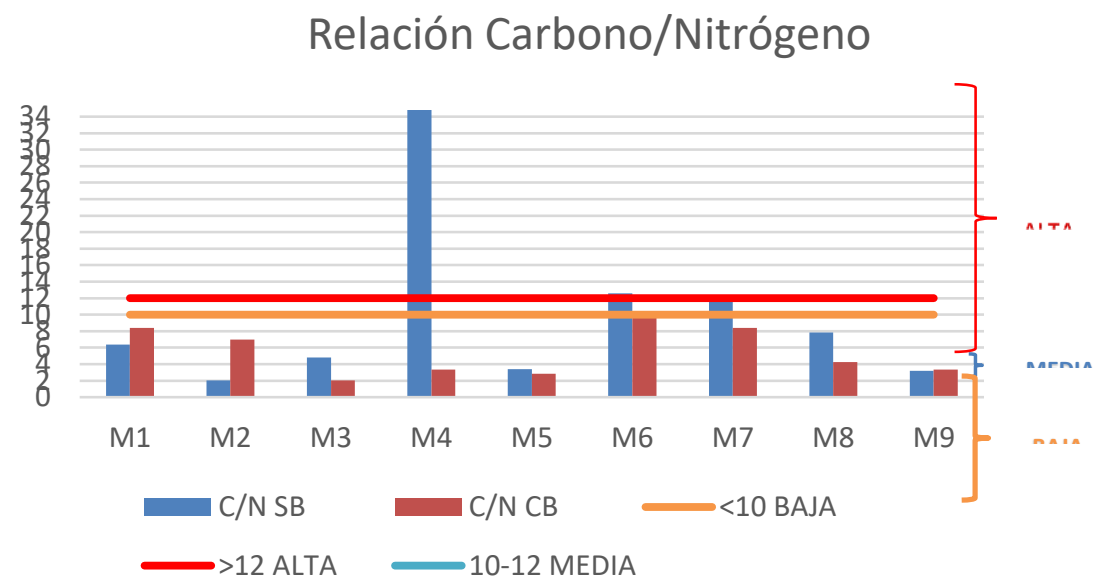

Fuente: Calderón y Núñez, Ecuador, 2018

Gráfica 8 Materia Orgánica en suelos sin bioactivador y con bioactivador

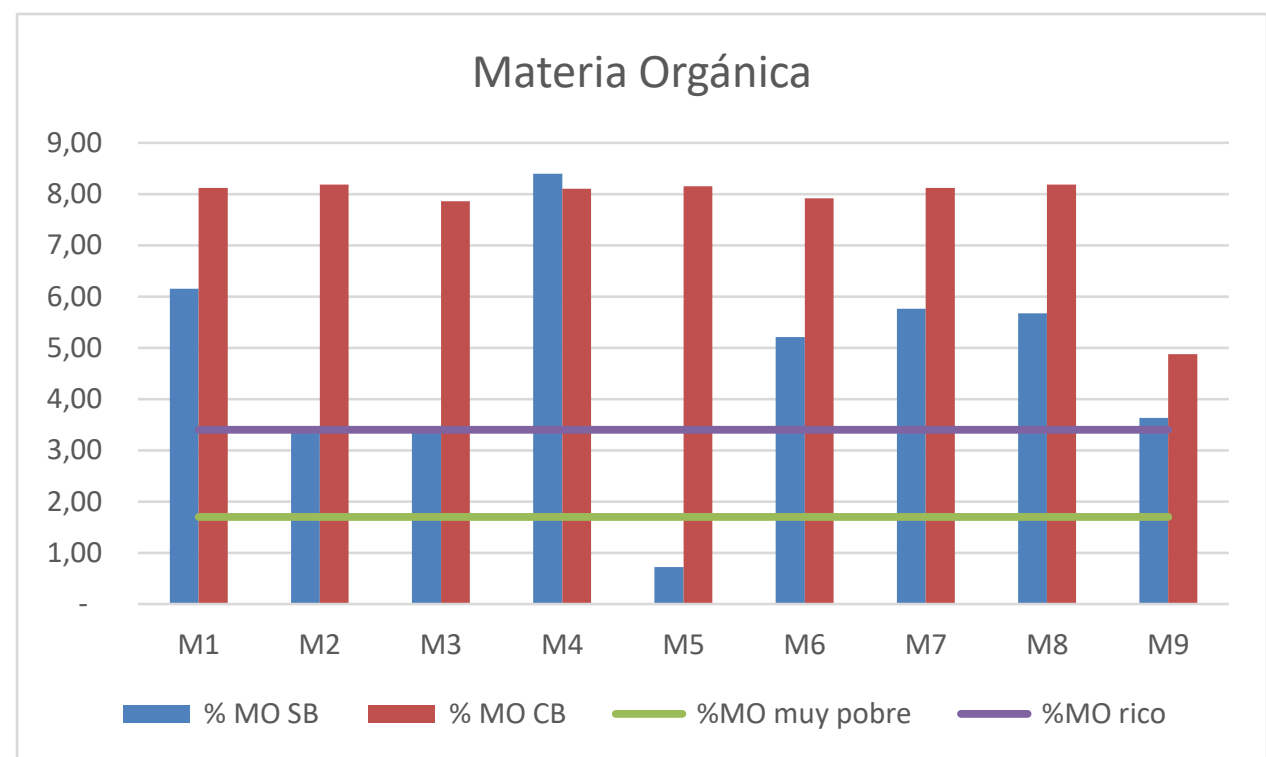

Fuente: Calderón y Núñez, Ecuador, 2018 


\section{Referencias bibliográficas.}

Agrios, G., 2008. FITOPATOLOGÍA = Plant pathology. Segunda ed. México: Limusa.

Almorox A., J., López B., F. \& Rafaelli, S., 2010. La degradación de los suelos por erosión hídrica. Primera ed. Murcia: Universidad de Murcia.

Aquiahuatl R., M. d. 1. A. \& Pérez C., M. d. L., 2004. Manual de prácticas del laboratorio de Microbiología General. Primera ed. México D.F.: Universidad Autónoma Metropolitana, Unidad Iztapalapa.

Ardila, Y., 2013. Patogenicidad de hongos entomopatógenos sobre Eurhizococcus colombianus Jakubski (Hemiptera: Margarodidae), plaga de Mora (Rubus glaucus Benth.), Medellin: Universidad Nacional de Colombia.

Becton, Dickinson and Company, 2005. Patrón de turbidez BBL preparado Mc Farland Turbity Standard No. 0.5, Maryland: BENEX Limited.

Bell, D. K., Wells, H. D. \& C., M. C. R., 1982. In Vitro Antagonism of Trichoderma species Against six Fungal Plant Pathogens. Phytopathology, April, 72(1), pp. 379 382.

Caballero-Mellado, J., 2006. Microbiología agrícola e interacciones microbianas. Revista Latinoamericana de Microbiología, Abril - Junio, 48(2), pp. 154-161.

Cano, M. A., 2011. Interacción de microorganismos benéficos plantas: micorrizas, Trichoderma spp y Pseudomonas spp. Una revisión. Rev. U.D.C.A Act. \& Div. Cient, 2(14), pp. 15-35.

Casanova Olivo, E. F., 2005. Introducción a la ciencia del suelo. Segunda ed. Caracas: Consejo de Desarrollo Científico y Humanístico.

Casas Flores, R., 2011. El suelo de cultivo y las condiciones climáticas. Primera ed. España: Paraninfo S.A..

Cepeda-Siller, M. \& Gallegos-Morales, G., 2004. Evaluación de la efectividad biológica, de biostat Paecilomyces lilacinus (Thom) Samsom, para el control de nemátodos en papa (Solanum tuberosum L.) en Navidad, Galeana, Nuevo León, México.. Revista Agraria, 1(3), pp. 349-359.

Chávez-García, M. y otros, 2013. Efeito de substrato e exposição à luz na produção de uma cepa de Trichoderma sp.. Universitas Scientiarum, 13(3), pp. 245-251.

Clayton, S. F., Sandhills, R. R. \& Hampton, J. W., 2013. The carbon cycle - Advanced (El ciclo del carbono - avanzado). Primera ed. Houston: Rice University.

Coyne, M., 2000. Microbiología del Suelo: un enfoque exploratorio. Primera ed. Madrid: Editorial Paraninfo.

Cruz-Velasco, L., 2007. Tipos de suelos desde el punto de vista de la mecánica de suelos. Popayán, Universidad del Cauca, pp. 19-20. 
Fernández Barbosa, R. J. \& Suárez Meza, C. L., 2009. ANTAGONISMO IN VITRO DE Trichoderma harzianum Rifai SOBRE Fusarium oxysporum Schiecht f. sp passiflorae EN MARACUYÁ (Passiflora edulis Sims var. Flavicarpa) DEL MUNICIPIO ZONA BANANERA COLOMBIANA. Revista Facultad Nacional de Agronomía, 62(1), pp. 4743 - 4748.

Fernández, O., 2015. Tecnologías para la Producción de Biopesticidas a base de hongos entomopatógenos y su control de Calidad. Habana: Laboratorio de Hongos Entomopatógenos INISAV.

GAB Sistemas Analíticos S.L., s.f. CÁMARA THOMAY NEUBAUER IMPROVED PARA EL RECUENTO DE LEVADURAS (TIRAJE). [En línea Available at: http://shop.gabsystem.com/data/descargas/Camara\%20Thoma\%20Neubauer_SP.pdf [Último acceso: 24 Febrero 2018].

GAD Cacha, s.f.. G.A.D PARROQUIAL CACHA. [En línea] Available at: http://www.cacha.gob.ec/

Gliessman, S. R., s.f. Agroecología: procesos ecológicos en agricultura sostenible. s.l., s.n.

Harman, G., 2010. Descripción general de los mecanismos y usos de Trichoderma sp. Fiitopatología. Estados Unidos: s.n.

Hernández J., A. y otros, 2006. El suelo: Fundamentos sobre su formación, los cambios globales y su manejo. Primera ed. Tepic: D. R. Universidad Autónoma de Nayarit.

Hernández J., A. y otros, 2010. Fundamento de la estructura de suelos tropicales. Primera ed. Tepic(Nayarit): Universidad Autónoma de Nayarit.

Hernández, A. y otros, 2008. EL SUELO: FUNDAMENTOS SOBRE SU FORMACIÓN, LOS CAMBIOS GLOBALES Y SU MANEJO. Primera ed. Tepic: Universidad Autónoma de Nayarit.

Ibáñez, J. J., 2008. Degradación del Suelo y Pérdida de Recursos Edáficos: Una Introducción. Madrid: Fundación para el conocimiento.

Kas, D. C. L., 1996. Fertilidad de Suelos. Pirmera ed. San José: EUNED.

L. do Prado, W. \& Veiga, M. d., 1994. Relación entre erosión y pérdida de fertilidad del suelo. Chile, FAO.

López, T., Dominguez, L. \& Garcia, J., 2007. Arreglo estructural de un consorcio microbiano de interés alimentario en la producción de vinagre. Revista Scielo Colombia, Issue 6, pp. 12-16.

Martín Sánchez, I., s.f.. Diversidad Microbiana. [En línea] Available at: $\underline{\text { http://diversidadmicrobiana.com/index.php?option=com_content\&view=article\&id=6 }}$ 
90\&Itemid $=771$

[Último acceso: 21 Febrero 2018].

Martinez, B., Infante, D. \& Reyes, Y., 2013. Trichoderma spp. y su función en el control de plagas en los cultivos. Rev. Protección Vegetal, Ene-Abr.Volumen 28.

Matta C., $\quad$ R., $2007 . \quad$ UDEC. [En Available at: $\underline{w w w 2 . u d e c . c l / ~ r m a t t a / S u e l o s / i n d e x . h t m l ~}$

Morales Gallego, M. L., 2009. LOS HONGOS, Sevilla: CSIF.

Moreira, F. M. S., Pfenning, L. H. \& Magalhaes de Abreu, L., 2012. Hongos del suelo saprófitos y patógenos de plantas. Primera ed. México: (c) Instituto Nacional de Ecología.

Narvaez R, W. V., 1986. PERDIDA DE NUTRIENTES DEL SUELO POR EFECTO DE LA EROSION HIDRICA, BAJO DIFERENTES SISTEMAS DE SIEMBREA EN EL CULTIVO DE AVENA: DPPF-96R-HKWU. Quito: INIAP Archivo Histórico.

Ochoa Carreño, D. C., 2010. Una metáfora biológica aplicada ala asociatividad empresarial en cadenas productivas agropecuarias. Revista Facultad de Ciencias Económicas, 29 Noviembre, XVIII(2), pp. 55-74.

Ortíz M., J. y otros, 2013. In vitro inhibition from native isolates of Trichoderma against commercial strain T22. Revista Colombiana de Biotecnología, 15(1), pp. 126-136.

Passalacqua, N., Cabrera \& RENALOA, 2014. ANÁLISIS MICROBIOLÓGICO DE LOS ALIMENTOS. Buenos Aires: INAL - ANMAT.

Peña S., R. R. \& Páez M., J. E., 2014. Fitopatología General. Guía para el cálculo de la concentración de inóculo. Tunja: Universidad Pedagógica y Tecnológica de Colombia.

Q.F.B. de Fes-Cuautitlan-UNAM Mexico, 2015. microbitos blog. [En línea] Available at: http://microbitosblog.com/2015/04/28/pseudomonas-aeruginosa-pputida-p-fluorescens-morfologia-medios-de-cultivo-enfermedades-y-mas/

[Último acceso: 21 Febrero 2018].

Quishpi, L. y otros, 2015. ACTUALIZACION PLAN DE DESARROLLO Y ORDENAMIENTO TERRITORIAL GAD-CACHA 2015. Riobamba: Consejo Parroquial de Cacha.

Rittman, B. E. \& McCarty, P. L., 2001. Biotecnología del Medio Ambiente. Principios y Aplicaciones. Primera ed. Madrid: McGraw-Hill.

Romero Villagra, D. C., 2004. Efectos de la aplicación de Paecilomyces lilacinus en el control de Meloidogyne spp. en pepino. San Antonio de Oriente: Universidad Zamorano. 
Ruda de Schenquer, E. E., Mongiello, A. \& Acosta, A., 2004. Contaminación y salud del suelo. Primera ed. Santa Fé: Ediciones UNL.

Saz Achuelo, M., 2010. Microorganismos del suelo y biofertilización, Madrid: Asociación Vida Sana.

Stille, D. R., 2005. Erosion. How Land Forms How It Changes. $1^{\circ}$ ed. Minneapolis: Compass Point Books.

Tortora, G. J., Funke, B. R. \& Case, C. L., 2007. MICROBIOLOGY: an introduction 9th ed.. Novena ed. Madrid: Editorial Médica Panamericana S.A..

Toy, T. J., Foster, G. R. \& Renard, K. G., 2002. Soil Erosion: Process, Prediction, Measurement, and Control. First ed. New York: John Wiley \& Sons.

UNIVERSIDAD NACIONAL DE CÓRDOBA, 2015. GUIA DE ACTIVIDADES PRACTICAS. MICROBIOLOGÍA AGRÍCOLA. Córdoba: Universidad Nacional de Córdoba. F.C.A..

Velasco Trejo, J. A., 2002. Tecnologías de remediación para suelos contaminados. Primera ed. Mexico D.F.: Instituto Nacional de Ecología.

Velázquez-Gurrola, A. \& Ramos-Alegría, M., 2015. Beneficios de microorganismos solubilizadores de $\mathrm{P}$ y $\mathrm{K}$ en la recuperación y mantenimiento de suelos agrícolas. LIMA, PERU, Perú ProHass, pp. 495-499.

Villalobos J., F., Mateos, L., Orgaz, F. \& Fereres, E., 2009. FITOTECNIA: Bases y tecnologías de la producción agrícola. Segunda ed. Madrid: Ediciones Mundi-Prensa.

Villegas, $\quad$ M., 2010. OriusBiotecnologia. [En Available at: http://www.oriusbiotecnologia.com/tecnica/128-trichoderma-perscaracteristicas-y-su-potencial -biologico-en-la-agricultura-sostenible

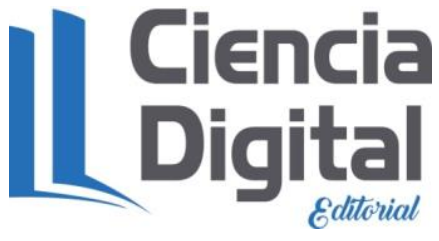


Para citar el artículo indexado.

Calderón C. \& Núñez S. (2018). Elaboración de un Bioactivador a partir de un consorcio microbiano de los géneros: Pseudomonas spp., Paecilomyces spp. y Trichoderma spp. Como posible reactivador de suelos erosionados de la parroquia cacha, provincia de Chimborazo. Revista electrónica Ciencia Digital 2(4.2), 88-114. Recuperado desde: http://cienciadigital.org/revistacienciadigital2/index.php/CienciaDigital/article/view/203/18 $\underline{0}$

\section{【 Ciencia}

El artículo que se publica es de exclusiva responsabilidad de los autores y no necesariamente reflejan el pensamiento de la Revista Ciencia Digital.

El articulo queda en propiedad de la revista y, por tanto, su publicación parcial y/o total en otro medio tiene que ser autorizado por el director de la Revista Ciencia Digital.
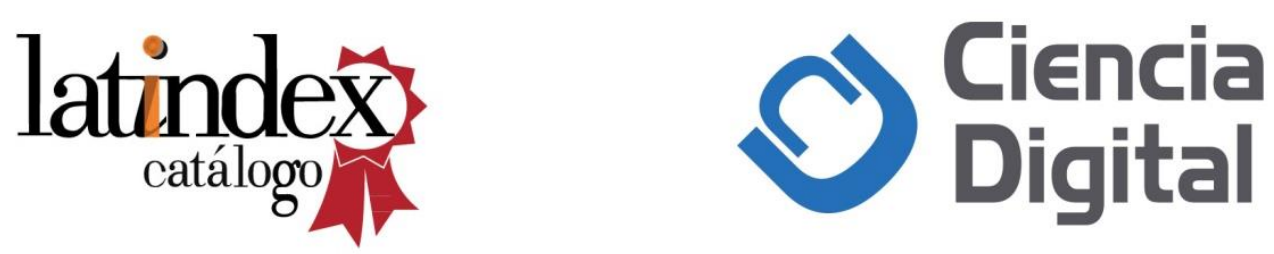